\title{
Representation and Identity Construction of Ethnic Minorities from Discourses in Government Media
}

\author{
Guru Prasad Poudel, Lecturer \\ Kathmandu Shiksha Campus
}

\begin{abstract}
Discourse is the commonsense language that represents the society, culture, social groups, group behaviors, socio-cultural identities and political ideologies. It signifies communication as a whole. Media gives space for people's voices in its programs and publications. In the same way, media is a common representative of the voices of all the ethnic communities regardless of majority or minority in its true principle. However, the languages and voices of all ethnic communities have not been represented in the discourse of government media in Nepal. In such a situation, this research aimed to; examine the representation of ethnic-minority languages in the discourses of government media of Nepal; critically assess the socio-cultural and political cognitions of the ethnic-minorities throughout the discourses in those media, and; identify the various identities constructed by the speakers of ethnic-minority languages through the discourses in government media. The finding of the study shows that out of 125 languages spoken in Nepal only 22 ethnic languages are represented in the discourse of Nepalese government media and the ethnic minority felt themselves being included within the national discourse when they found their discourses being represented in public media.
\end{abstract}

Keywords: Government media, Representation, Identity construction, Ethnicminority

\section{Background of the study}

Government media (i.e. media houses established and regulated by the policy of state) are the public forums of communication. They have high coverage and they can impart huge amount of information to the large group of audiences at a time (Durant \& Lambrou, 2009). They should act as the common representative to all. However, all ethnic communities are not treated equally in the discourse of government media. In such a context, it is significant to examine how the ethnic discourses (i.e. especially the voices of ethnic-minorities) have been represented in government media and what sorts of cognitions of representation and identities have been constructed so far by the ethnic-minorities through the representation of there discourses in government media. 
The situation of unequal representation of ethnic languages in government media has triggered me to study on the very issue of 'Representation and identity Construction of Ethnic Minorities from Discourses in Government Media'.

To be specific, Media plays a key role in the construction and reproduction of opinions about people, society, culture, representation, identity and the cognition of people's discourses (Van Dijk, 1995). The media convey public knowledge, as well as express implicit opinions i.e. peoples' intention, sense of affiliation, ideology, politics and hegemony about social groups and events. More importantly, the mass media provide on ideological frame work for the interpretation of inherent cultural, social and political ideologies of the ethnic groups. Even media reproduce socio-cultural beliefs about the representation of peoples' discourses. Discourse is a social practice of language use and often synonymous to text (Mills, 2004). It is used as written and spoken form of language in communication that conveys broad linguistic, historical, cultural and socio-political meaning (Mc Carthy, 2010). Discourse is a supra-sentential level of language that is seen in the form of communicative event which can be viewed from socio-linguistic as well as disciplinary perspective. Hence, discourse is a unity of language in communication which is unified, purposive and meaningful in the context of its use. The study of discourse in terms of its meaning, purpose and forms of organization is discourse analysis (DA). Discourses in media can represent the sociopolitical identities and cultural ideologies. Identity is a social form that gives a respect to the people as in the form of their position or feelings. Gandy (1998, as cited in Devroe, 2003) argues that not everyone who accept their classification as a member of a racial group shares the same levels of comfort or ease with that assignment. People often feel themselves privileged and represented when their discourses are given due space in the national media (Saeed, 2007). In identity construction theory, Hall, (2002) expresses that identity is gradually constructed via public discourse. The discursive practices existed so far in public media involve people in meaning making process and in the reconstruction of new identities. Identity theory is introduced by Colley and Mead in 1970s (Cerulo, 1997). Identity studies have been relocating to the site of the collective, with gender/sexuality, race/ethnicity, and class forming the 'holy trinity' of the discursive field (Appiach and Gates 1995, p.1). People often realize the identity of 'I', 'me', and 'other' in milieu void of place, the establishment of 'communities of the mind' and the negotiation of co-present and social identities through their representations in media (Cerulo, 1997). The evaluation of the media discourse and its role in the representation of social-culturally underprivileged group of people in the mainstream discourse is worth to study. Media play crucial role in creating a multi-ethnic public 
sphere, where diverse groups can feel they are being represented in the media and they are making a contribution (Husband, 2000). Ethnic minorities' representation in the media, their media use and their level of participation in media production (Devroe, 2003) are all considered as indicators of social participation and integration. The relationship between media and ethnic minorities and the function of the media in a multicultural society have become the interest of academicians, media producers and policy makers (Terwal, 2002).

Recent studies (i.e. Cottle, 2000; Wodak \& Busch, 2002; Saeed, 2007) have discussed the role of mass media as a space for representation of identities and cultural ideologies. Those studies have exerted that media has a high coverage not only in terms information and audience, equally it can represent ethnic identity and culture in and across the country. However, the issue of representation and identity construction through media has not yet been carried out by the researchers in our context.

The representation of a few languages amongst the languages spoken in the country motivated me to study on what languages and ethnic culture have been represented in the national media of Nepal. I have also experienced peoples' different cognition regarding the role of media discourse in the representation and identity construction of ethnic group. When I started to hear and read media language, I found disparity among the discourses of ethnic community in media text and programme. Especially, I found that very few languages of minority groups were given due space in the media. Such a situation helped me to raise a curiosity on how do the minority ethnic groups feel about their representation in national media and what sorts of identity have been constructed by them. In this study, I have focused on four aspects in this study viz: languages represented in the discourse of government media (i.e. Gorkhapatra Daily, Radio Nepal and Nepal Television), cases of representation of ethnic minorities in those media and cognition and identity construction of ethnic minority group through the representation of their discourse in those media. Being specific to the Nepalese context, the earlier researchers have not made any significant contribution in the field of media discourse analysis considering the issue of representation and identity construction. So through the study I tried to bridge such a gap in the research literature. I believe that this study would provide insights on representation of ethnic-discourses in media and the identities constructed by the ethnic-minorities throughout the discourses in government media.

To be specific, this study attempted to address the following questions:

- How and in which forms the discourses of ethnic minorities of Nepal have been represented in the discourse of government media of Nepal? 
- What are the socio-cultural and political cognitions of the ethnic-minorities through the representation of their discourses in government media and how do the speakers of ethnic-minority languages construct their identities through the discourse in media?

\section{Methodology}

This was a qualitative study. It employed a critical discourse analytical approach. I used this approach to examine the representation and identity construction of ethnic minorities through the use of their discourse in government media. The participants in this study included three media stakeholders and five minority language speakers who were purposively selected. A semi-structured interview format and focus group discussion was held to collect the data. I employed interpretive method of analysis. The data were de-contextualized and re-contextualized. During de-contextualization, the data was separated from the original context of individual cases and assigned codes to units of meaning in the texts. In re-contextualization, the codes were examined for patterns and then reintegrated, organized and reduced the data around central themes and relationships drawn across all the cases and narratives. So, while analyzing and interpreting the data in order to derive the findings, at first the data were codified and the themes were developed for processing the data from interview and FGD.

\section{Discussion of the study}

The discussion of the study has been subsumed into the following thematic form based upon the focus of the study.

\section{Representation of ethnic-minority languages in government media}

Finding out the representation of ethnic-minority languages in those media was one of the basic concerns of this study. The interview with two media stakeholders and two representative speakers of ethnic-minority languages showed that very few ethnic languages had been represented in the public media of Nepal, i.e. Radio Nepal, Nepal Televisison and Gorkhapatra Sansthan. In response to the question asked in interview, the participants viewed that among the 123 languages spoken in Nepal (CBS, 2012), a few of ethnic languages are represented in the discourse of government media. According to them, The Gorkhapatra Daily represented 22 languages including Tharu, Bhojpuri, Jhagand, Maithili, Magar-dhut, Gurung/Tamu, Tamang, Lhomi, Sunuwar, Newari, Awadhi, Rajbanshi, Bhote, Doteli, Topkegola and Malegu languages in its issue periodically. Similarly, Radio Nepal included only ten languages in its news bulletin and in other generic programs. However, the advertisements, notices and information are represented in many other languages. The dominant language that has 
been used in government media is Nepali. It might be the result of power, dominance and hegemony. It is because Nepali is the national language, most of the speakers speak in Nepali and it has been used as the language for communication, education and official purposes. As the evidence of the representation of ethnic-minority languages in government media, following interview-excerpt from the interview is presented here:

We have just included 22 ethnic languages in our media. We have to focus on the readers. And...the readers in majority speak Nepali language and do not get the ideas in other nation's language. In Gorkhapatra Daily, we have been publishing news and feature-articles in different languages. As the evidences, we publish news and accessories in Tharu language, Bhojpuri, Jhagand, Maithili, Magar-dhut, Gurung/ Tamu, Tamang, Lhomi, Sunuwar and Malegu language (From media representative-1).

The above excerpt clarifies how the ethnic minority languages are represented in government media. In the same concern, another media representative said:

In Radio Nepal, the....the news and other programs are conducted in 10 different languages from the central station and other regional stations. In my opinion, local languages should be promoted through local stations and channels. (from media representative- 2).

The above excerpt also signifies that the representation of minority's discourse in government media is quite marginal. From the analysis of data, it can be interpreted that disparity is created among the languages spoken in Nepal especially in the form of representation in the discourse of government media. I also interviewed with the speakers of ethnic-minority languages. One of the excerpts is given below:

Government and other media can preserve and promote indigenous languages. However, it is pity to say that government media have created linguistic hegemony. They have been broadcasting news and other generic program. However, the minority languages have been excluded in those media. But at present, little bit space is given in news broadcasting and entertaining program.

Through the lens of critical discourse analysis, it can be interpreted that many ethnic languages spoken in Nepal are excluded in the discourse of government media. Those languages are simply used for communication in their respected locality among the people who share the same language. Such a situation has made minority languages powerless. Though language is a cultural heritage and it should be preserved in any cost, the attempt for preserving and promoting minority languages has not been made so far.

\section{Cases of representation of ethnic-minority languages}

Another concern of this study was to examine the different cases of representation of ethnic minority languages in government media. The data from the interview and 
FGD show that minority languages have been represented in the form of news bulletins, generic programs, advertisement and public information, entertainment (i.e. songs and comic literature) and folk culture. The following interview excerpts give the evidence of representations:

In Gorkhapatra Daily, we have been publishing news and feature-articles in different languages. In each days of a week, we have a separate column for ethnic minority language. As the evidences, we publish news and accessories in many ethnic languages. The cases of news, socio-cultural diversity, peoples' life-style and achievements, developmental and educational events, entertaining information, and even notices and advertisements are the major ones. (From media representative-1)

Similarly, another representative said:

Personally, I have observed different cases of representation in government media. It is....ummm... what to say...mostly advertisement, notices and public awareness information are broadcasted in different languages. News is also broadcasted in many languages, however, comparatively the other generic programs are not in greater extent.

In the voice of ethnic minority speaker:

Only a few news bulletins, generic program and feature writing have been represented in those media. I am from Tamang ethnic community, Radio Nepal and Nepal television broadcast news in Tamang once in a day. Gorkhapatra publishes an issue periodically. Smilarly, 'Tamang Sello' and 'Tamang Sanskrit Bisesh' are also broadcasted in government media. I mean ... its is not inclusive.

Taking reference of the excerpts above, it has become clear that the cases of representing ethnic-minority languages include news bulletin, feature articles, advertisements, culture-specific program and public awareness information. But they are not frequent in those media. The limited use of ethnic-minority language in the discourse of government media has made the ethnic-minorities disappointing.

\section{Socio-cultural and political cognition of the representation}

From the analysis and interpretation of the data related to the socio-cultural and political cognitions developed by the participants so far, it has been found that the speakers of ethnic-minority languages construct the cognitions of developing a sense of affinity, belongingness, respected, independent and socio-culturally rich. Intercultural competencies, cross-cultural awareness, communicative competence, politico-cultural intellectuality and feeling of being privileged were the major constructs of cognitions that the participants perceived through their discourse in government media. To support the analysis, some excerpts from the interview have been included here: 
People can have the feeling of affinity, solidarity, socialization, getting rights and sense of independence by an act of representing language in media discourse.(From media representative-2)

Similarly, another participant said:

People get many things done through their discourse. The minority speakers may feel outsiders whenever they don't find their voices in media. They understand the world around by means of language they possess. It may present them privileged one. Their socio-cultural identity is constructed via language and they will have new forms of understandings.(From media representative-1)

Likewise, in the words of ethnic minority speaker:

When I get my language used in public discourse in media, I feel privileged. I find that my language also has something unique than others. I develop a sense of affinity, belongingness, respected, independent and socio-culturally rich.

From the above interview excerpts, it can be inferred that people construct different forms of socio-cultural and political cognitions through the discourse. They can feel themselves politically powerful and privileged, culturally rich and resourceful, socially attached and linguistically autonomous. However, the inequality in the inclusion of language in mainstream media has created a sense of being excluded to the ethnicminorities.

\section{Identities constructed through discourses in media}

Finally, the study envisaged to identify the identities constructed by the speakers of ethnic- minority languages. After the analysis and interpretation of the data, it has been inferred that the participants of the study constructed the identities like feeling a sense of represented, privileged, belongingness, linguistically competent, culturally strong, politically powerful, socially attached and emotionally satisfied whenever they get their discourses in government media. However, they viewed that the mainstream media of Nepal have presented them as outsiders, marginalized, underprivileged, nonrepresented and kept them isolated. As per the reason, they expressed that their ethnic languages are not given due respect in media discourse. The following excerpts are the evidences to show identities constructed by the speakers of ethnic minority languages:

Discourses in media raise awareness, inform, persuade, give justice, advocate and ultimately spread the identity. ...umm..I have constructed the identity of belongingness, inclusiveness and getting respect as the citizen of a nation throughout the discourses in media. For me, language is the matter of identity.(From the representative speaker of ethnic-minority) 
When I get my own discourse in media, I feel quite happy. I guess I am linguistically rich, and socially representated. (From the representative speaker of ethnic-minority)

From the ideas expressed in above excerpts, I come to conclude that discourse in media is a matter of identity construction. The way that ethnic-minorities' discourses are represented in mainstream media has an impact on constructing various identities to the people abide with those discourses. From the evaluation of the data collected, the participants of this study constructed the identities as being underrepresented, represented in a stereotypical way, represented negatively, and represented as culturally abnormal, as unimportant, as dependent, as invisible, as underprivileged, as marginal and the outsiders of the dominant discourses.

\section{Findings, conclusions and implications}

The findings of the study exert that though language is a cultural heritage and it should be preserved in any cost. However, the attempt for preserving and promoting minority languages has not been made so far. Among many languages spoken in Nepal, very few of them (i.e. 22 in Gorakahpatra National Daily, 16 in Nepal Television and 18 in Radio Nepal) are represented in the discourse of government media. As the common forums, the government media should give justice to all languages in either of the ways for the inclusive representation of languages in media.

Regarding the cases of representing ethnic-minority languages, the government media of Nepal have simply included ethnic languages in news bulletin, feature articles, advertisements, culture-specific program and public awareness information. But they are not found frequent in those media. The limited use of ethnic-minority language in the discourse of government media has made the ethnic-minorities disappointed. The linguistic policy of the government, multilingual education and social representation system, increasing awareness in the use of language, linguistic human rights and policies and politics of language could be the forcing elements to represent the ethnic minority languages in government media.

Concerning to the socio-cultural and political cognition through the representation of ethnic discourses in government media, the participants of the study felt themselves politically powerful and privileged, culturally rich and resourceful, socially attached and linguistically autonomous. However, the inequality in the inclusion of language in mainstream media has created a sense of being excluded to the ethnic-minorities. So, much attention should be given towards the representation of ethnic discourses in public media so that the minority languages can be linguistically strong, culturally rich, socially attached and politically equal in power. 
As the study envisages to identify the identities constructed so far by the speakers of ethnic-minority languages, it has been concluded that the participants of this study constructed the identities as being underrepresented, represented in a stereotypical way, represented negatively, represented as culturally abnormal, as unimportant, as dependent, as invisible, as underprivileged, as marginal and the outsiders in the government media. It might be the result of nominal representation of ethnic-minorities' discourses in media. However, whenever they found their discourse being represented in national media then they could construct the identities of feeling a sense of belongingness, developing cultural heritage, enhancing inter and cross cultural competencies, forming new forms of social, cultural and political ideologies, and multilingual ethnic identities as the identities constructed from the discourses in government media. (Mr. Poudel has been pursuing M.Phil in English Language education (ELE) from the Graduate School of Education, T.U. Kirtipur and working as Teaching Assistant in the Department of English Education, T.U., Kirtipur.)

\section{References}

Castells, S. (2002). Race, rationalization and the media: A review and update of research. Sage Race Relations Abstracts 17: 3-57.

Cerulo, K.A. (1997). "Identity construction: New issues". New Directions. The Journal of Arj Annual Reviews. FU Berlin pp 385-409.

Cottle, S. (2000). Ethnic minorities and the media. Buck Ingham: Open University Press.

Devroe, I. (2003). Allochtonen en aanverwante thema's in de Vlaamse pers. Tijdschrift voor Communicatiewetenschap, 30 (2): 56-76.

Durant, A. \& Lambrou, M. (2010). Language and Media. London and New York: Routledge. Fairclough, N. (1992). Critical discourse analysis. London: Pearson.

Hall, S. (2002). Racist ideologies and the media. New York: New York University Press.

Husband, C. (2000). Media and the public sphere in multi-ethnic societies. In: Cotlle, S. (Ed.) Ethnic minorities and the media (pp 199-214). Buckingham: Open University Press.

Mc Carthy, M. (2010). Discourse analysis for language teachers. Cambridge: Cambridge University Press.

Mills, S. (2004). Discourse: The new critical idiom. London: Routledge.

Potter, J. \& Wetherell, M. (1987). Discourse and social psychology: Beyond attitudes and behavior. London: Sage.

Saeed, A. (2007). Media, racism and islamophobia: The representation of Islam and Muslims in the media. Sociology Compass: Blackwell Publishing Ltd.

Van Dijk, T. (ed.) (1995). Handbook of discourse analysis: volume 3, Discourse and dialogue. London and san Diego: Academic Press.

Van Dijk. T. A. (2001). Principles of critical discourse analysis. Discourse \& Society, 4(2), 249-283.

Wodak, R. \& Busch, B. (2002). Approaches to media texts. Annual review of prolegomena, 28.105-127. 